\title{
Playing with the Red Planet
}

\section{Terraforming Mars}

By Jacob Fryxelius

STRONGHOLD GAMES: 2ND EDN, 2017.

US\$69.95

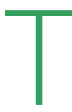

erraforming is a planetary-scale engineering project - out of reach with current technology - for the purpose of making a planet habitable by humans. The game Terraforming Mars manages to reproduce this problem for the Red Planet in a sufficiently scientific way to largely avoid snarky comments by planetary scientists. The game designer Jacob Fryxelius, who has a $\mathrm{PhD}$ in chemistry, employs several ways to reflect the scientific ideas behind terraforming in the game mechanics. For example, the game ends when specific criteria are reached: a temperature of $+8^{\circ} \mathrm{C}$, oxygen abundance at $14 \%$, and $9 \%$ of the surface - the playing board is a wonderful illustration of Valles Marineris - covered in liquid water.

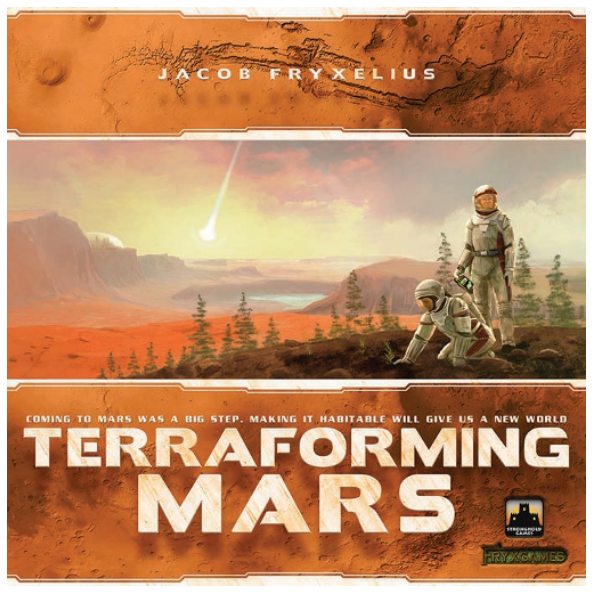

In addition, the game ties these physical conditions together in a way that conveys the feeling of a complex and intertwined global system. For example, various plant species cannot be introduced until the temperature is above a certain threshold, depending on their individual energy needs. Thus, players would probably start populating Mars with lichens rather than trees, simulating what scientists believe a 'real' terraforming process would look like. Set in a moderately far future, the game also has a good dose of science fiction (for example, the possibility of colonizing Ganymede) that appeals to fans of the genre. Concerning the game mechanics, Terraforming Mars employs a clever system that combines cards, representing events or various projects related to terraforming, with resource management. The only warning: it's not for beginners, as there are many symbols on the cards and strategies can become very complex. In short, this is an entertaining and educational game that appeals to gamers, science fiction enthusiasts and scienceoriented players alike.

REVIEWED BY LUCA MALTAGLIATI

Luca Maltagliati is an associate editor at Nature Astronomy. 